\title{
The infections of Saint-Louis: possible involvement of malaria
}

\author{
Eric Faure ${ }^{1}$
}

Accepted: 23 November 2015/Published online: 14 December 2015

(C) Springer Science+Business Media New York 2015

I read with great interest Charlier et al.'s [1] report of the microscopic detection of Schistosoma in embalmed viscera of Saint-Louis. The authors mentioned that: "Louis IX, King of France... died... during an epidemic episode of "plague" in the city of Tunis... Reasonably, Schistosoma did not play a direct role in the mechanism of death for Saint-Louis, whose exact cause of death remains unknown." However, a plausible retrospective diagnosis of the illness(es) that killed Saint-Louis may be proposed, based on an analysis of sources written by eyewitnesses [2]. During his military campaigns, Saint-Louis, and his troops, seems to have often suffered from dysentery and fevers; the latter were frequently intermittent which is consistent with malaria. In 1242, Saint-Louis contracted malaria in France; after relapses, in 1244 he developed cerebral malaria with coma and during this episode vowed to go on a crusade if he healed. "Flows of belly" and "tertian fevers" are mentioned. During his first crusade (in Egypt in 1250) he suffered from "double tertian fevers" and dysentery. After he returned, he was seriously ill several times, but further details are not available. Before his departure for his second and last crusade, due to his poor physical condition he was unable to ride and so had to be carried. During this crusade in Northern Africa (1270) Saint-Louis exhibited the double symptoms of (continuous) fevers and dysentery. Interestingly, malarial fevers can also be continuous; moreover, malaria can exhibit gastrointestinal symptoms similar to dysentery and can also exacerbate the effects of gastrointestinal diseases [3]. In

Eric Faure

eric.faure@univ-amu.fr

1 CNRS, Centrale Marseille, I2M, UMR-7373, Aix-Marseille Université, 13453 Marseille, France addition, cases of intermittent fevers were mentioned during this crusade, e.g., one of Saint-Louis' sons who accompanied him was affected by quartan fevers [2]. SaintLouis was traditionally believed to have died from the (bubonic) plague. However, Charlier et al. [1] themselves mention this word in brackets. However, there is little support for this diagnosis; i.e., the epidemic that affected the French troops did not have the characteristics of a bubonic plague, and there was no mention of buboes [2]. Moreover, there was no disorganization of the French army since before leaving Africa, enabling the Crusaders to conclude a very favorable agreement with their adversaries. Saint-Louis therefore, probably suffered from chronic malaria associated with other infections. Although the authors have identified one of the parasites that were present, they could enhance their discovery by trying to detect causative agents of dysentery and malaria, such as Plasmodium, which might be present in large amounts in the blood vessels of the intestines.

\section{References}

1. Charlier P, Bouchet F, Weil R, Bonnet B. Schistosomiasis in the mummified viscera of Saint-Louis (1270 AD). Forensic Sci Med Pathol. 2015. doi:10.1007/s12024-015-9722-4.

2. Brachet A. Pathologie mentale des rois de France. Paris: Hachette; 1903.

3. Faure E. Malarial pathocoenosis: beneficial and deleterious interactions between malaria and other human diseases. Front Physiol. 2014;5:441. 